\title{
Section preparation of human marrow for light microscopy
}

\author{
JOHN T. DANCEY ${ }^{1}$, KURT A. DEUBELBEISS ${ }^{2}$, AND LAURENCE A. HARKER \\ with the technical assistance of J. GREENAWAY
}

From the Division of Hematology, Department of Medicine, University of Washington School of Medicine, Seattle, Washington 98195, USA

SYNOPSIS Preparation of human marrow sections has been studied systematically in order to facilitate accurate identification of marrow cells. Both of the methods developed involve embedding $\triangleright$ marrow cores in methyl methacrylate. In one, acrolein fixation is followed by staining of deplas- 을 ticized sections with eosine-y followed by azure II; in the other, neutrophilic forms are identified $\rightarrow$ by their esterase-specific reactivity in marrow fixed with neutral-buffered formalin. These preparations are suitable for quantitative studies of marrow cellularity.

The purpose of this paper is to report our experience in the preparation of sections of human marrow for light microscopy, and to describe two methods that permit reliable recognition of all normal cell types in marrow sections.

\section{Methods and results}

Marrow biopsies, taken from the posterior superior iliac spine with a Westerman Jensen (Ellis et al, 1964) or Jamshidi (Jamshidi and Swaim, 1971) needle, were placed immediately in fixative.

\section{FIXATION}

The following fixative techniques were evaluated: Zenker's fixative incubated for 24 hours at room temperature (Lillie, 1965); Zenker's fixative without acetic acid but with the same incubation conditions; glutaraldehyde at concentrations of $1.25 \%, 2.5 \%$, $5.0 \%$, and $6.25 \%$ in $0.1 \mathrm{M}$ phosphate buffer, $\mathrm{pH}$ $7 \cdot 2$, for 24 hours at room temperature, and at a $5.0 \%$ concentration in 0.065 and $0.15 \mathrm{M}$ phosphate buffer,

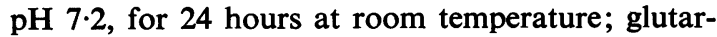
aldehyde-formol (glutaraldehyde $6.25 \%$ in $0.1 \mathrm{M}$ phosphate buffer, pH $7 \cdot 2$, with formalin $10 \% \mathrm{v} / \mathrm{v}$ ) for 24 hours at room temperature; neutral-buffered formalin $(10 \%$ formalin in $0.1 \mathrm{M}$ phosphate buffer,

\footnotetext{
${ }^{1}$ Present address: Division of Hematology, Montreal General Hospital, Montreal, Quebec, Canada 2Present address: Division of Hematology, Inselspital, Bern, Switzerland

Received for publication 15 January 1976
}

pH 7.2) for $12,16,18$, and 24 hours at room temperature and at $37^{\circ} \mathrm{C}$; and acrolein (distilled, EM grade, $\mathrm{N}_{2}$ sealed, Polysciences Inc, Warrington, $\mathrm{Pa}$, USA) at concentrations of $2.5 \%, 5.0 \%$, and $10 \%$ in $0.1 \mathrm{M}$ phosphate buffer, $\mathrm{pH} 7 \cdot 2$, for 24 hours at $\propto$ room temperature and at $37^{\circ} \mathrm{C}$.

The results are summarized in the table. Although $\frac{0}{3}$ marrow fixed with solutions containing Zenker's fixative appeared to be fairly homogeneous, cello shrinkage was prominent in comparison with marrow fixed with other agents. Addition of acetic acid was associated with additional distortion of $\frac{3}{3}$ cell contours, especially marked in cells of the erythroid series where cytoplasmic membranes became crenated. Although specific granules in eosinophils were well stained after Zenker fixation, $\stackrel{5}{7}$ neutrophil granules were not, and a non-specific $\frac{7}{8}$ cytoplasmic granularity of all cells further compromised histological identification.

Despite good preservation of both cytoplasm and nucleus by glutaraldehyde in well-fixed areas, $\mathrm{N}$ regional variation in fixation within individual $\omega$ sections was continuously troublesome. This artefact was marked in some preparations and minimal ine others fixed in an identical manner; substitution $\Phi$ with the other concentrations of glutaraldehyde ${ }^{+}$ failed to resolve the problem. The speed of infiltration was increased by carrying out fixation with $5 \%$ 우 glutaraldehyde at $37^{\circ} \mathrm{C}$ but the artefact remained. $\frac{\rho}{\square}$ The effect of buffer osmolarity was also assessed by@ fixing marrow biopsies with $5 \%$ glutaraldehyde in 0.065 and 0.15 molar phosphate buffer. No appre- 


\begin{tabular}{|c|c|c|c|c|c|}
\hline Fixative & Evenness of & Shrinkage of & Distortion of Cell Contour & \multicolumn{2}{|c|}{ Best Staining Method } \\
\hline Zenker-formol & Moderate & $3+$ & Moderate & $\begin{array}{c}1 \\
2\end{array}$ & $\begin{array}{l}\text { Esterase } \\
\text { Eosine-y + azure II }\end{array}$ \\
\hline Helley's solution & Moderate & $4+$ & Marked & 1 & Eosine-y + azure II \\
\hline Glutaraldehyde & Poor & $1-3+$ & Swelling of cells in poorly fixed zones & 1 & Eosine-y + azure II \\
\hline Glutaraldehyde-formol & Poor & $1-3+$ & Swelling of cells in poorly fixed zones & 1 & Eosine-y + azure II \\
\hline Neutral-buffered formalin & Good & $1-3+$ & None & 1 & $\begin{array}{l}\text { Esterase } \\
\text { Eosine-y + azure II }\end{array}$ \\
\hline Acrolein & Good & $1-2+$ & None & 1 & Eosine-y + azure II \\
\hline
\end{tabular}

Table Fixative evaluation

ciable difference was seen in marrow fixed using hypo-, iso-, or hyper-tonic buffer solutions, and variable fixation persisted. Well-fixed areas of marrow, stained adequately with azure II and eosine-y, permitted reliable identification of major cell species, but in poorly fixed areas cell identification was impossible because affinity for both basic and acid stains was markedly reduced. Addition of formalin to the glutaraldehyde fixative solution was without benefit.

Marrow fixed in neutral-buffered formalin for 18-24 hours showed variable shrinkage, but the overall preservation of cell size was better than that provided by Zenker fixation. Indeed, many areas showed no appreciable cell shrinkage, and even in areas of inadequate fixation with cellular swelling the staining characteristics were frequently intact. However, nuclear chromatin had a smudged appearance in young cells, especially those of the erythroid series, and specific granules in eosinophil and neutrophil granulocytes were not well stained. Primary neutrophil granules, although stained by azure II and toluidine blue, were obscured by nonspecific cytoplasmic basophilia. Treating the sections with sodium hypochlorite and potassium iodide (see Staining, below) did not improve the staining of these granules. Cells of the neutrophil granulocyte series stained intensely for esterase activity when naphthyl ASD chloroacetate was used as substrate (see Staining, below). Although esterase reactivity decreased with increasing time of fixation in neutralbuffered formalin, cell shrinkage was more pronounced when the period of fixation was less than 16 hours. Thus human marrow was fixed in neutralbuffered formalin for at least 16 hours and for not more than 18 hours.

Acrolein at $3.5 \%, 5.0 \%$, or $10 \%$ concentrations in $0.1 \mathrm{M}$ phosphate buffer, $\mathrm{pH} 7 \cdot 2-7 \cdot 4$, produced less cytoplasmic and nuclear shrinkage than the other fixatives evaluated. No cell distortion was seen. Marrow fixed with acrolein stained well with eosine-y and azure II or toluidine blue with good definition of nuclear chromatin and nucleoli and preservation of cytoplasmic detail (fig 1).

\section{DECALCIFICATION}

The decalcifying methods evaluated were: $5 \%$ nitric acid, 60 minutes at room temperature; $5 \%$ formic acid, 24 hours at room temperature; and $5 \%$ tetrasodium ethylene diamine tetraacetic acid (pH adjusted to 7 with $5 \mathrm{M}$ citric acid (Mori et al, 1965)) for 24 hours at room temperature and at $37^{\circ} \mathrm{C}$. The degree of decalcification was assessed by microscopic examination of stained sections.

Nitric acid produced rapid decalcification but caused cell shrinkage and a shift in stain affinity resulting in decreased basophilia and increased eosinophilia. Staining of neutrophil primary granules was not reliable.

Formic acid decalcification was slow, requiring 12-24 hours for a degree of decalcification achieved by $5 \%$ nitric acid in 30 minutes. This agent also caused cell shrinkage, and primary granules in neutrophils could not subsequently be stained.

With EDTA, decalcification was still incomplete at 48 hours. Increasing the temperature to $37^{\circ} \mathrm{C}$ accelerated decalcification, with adequate results after 24 hours. Despite incomplete removal of calcium, biopsies decalcified in EDTA could be sectioned in relatively soft methyl methacrylate and in hydroxyethyl methacrylate. Exposure to $\mathrm{Na}_{4}$ EDTA pH 7 at $37^{\circ} \mathrm{C}$ for 24 hours did not change the cell size, shape or stain affinity compared with undecalcified marrow. It was found, however, that undecalcified cancellous marrow cores, when embedded in sufficiently hard blocks of methyl methacrylate, could be sectioned easily at thicknesses ranging from 1 to $4 \mu$.

EMBEDDING, SECTIONING, AND MOUNTING The embedding media examined were paraffin, hydroxyethyl methacrylate, and methyl methacrylate. When hydroxyethyl methacrylate was used, a technique recommended by Ruddell was followed; 8-12 ml 2-butoxyethanol (Polysciences, Inc, Warrington, $\mathrm{Pa}$ ), 0.17 $\mathrm{g}$ benzoyl peroxide (Eastman Organic Chemicals, Rochester, NY), and 22 drops of pyridine (S. T. Baker, Hayward, Calif) were added to $50 \mathrm{ml}$ of the hydroxyethyl monomer 


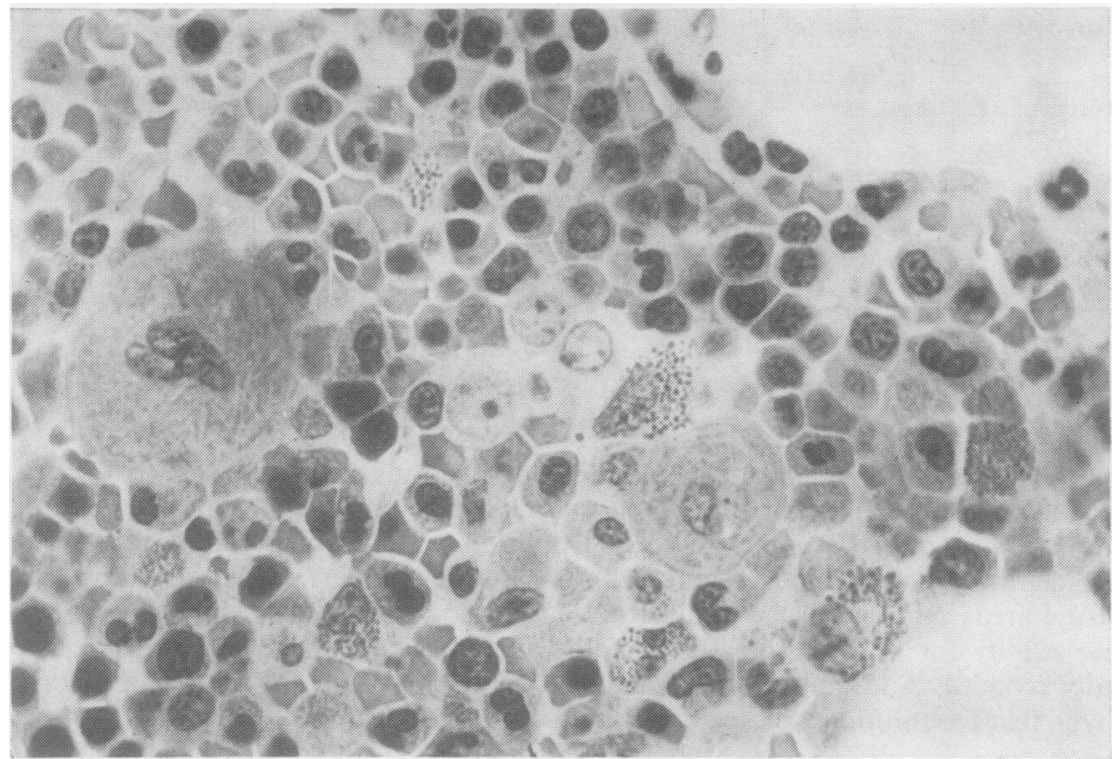

Fig 1 Sectioned human bone marrow. Marrow biopsies were obtained from the posterior iliac spine of normal subjects, fixed in acrolein, and embedded in methyl methacrylate. Sections were cut at $2 \mu$ thickness, using steel knives, and stained with eosine-y and azure $I I(\times 400)$.

(Rohm and Haas, Philadelphia, Pa) and dissolved by stirring for 15 minutes (Ruddell, 1967). Before embedding, the marrow tissues were decalcified in EDTA and dehydrated by successive 15-minute immersions in $30 \%, 50 \%$, and $80 \%$ ethanol followed by 30 minutes in absolute ethanol. The cores were then transferred to a 1:1 mixture of the hydroxyethyl methacrylate embedding solution and absolute ethanol for 30 minutes. Pieces of the marrow core, about $1 \mathrm{~cm}$ in length, were placed in 2-0 gelatin capsules partially filled with embedding solution and the capsules were then completely filled. The capsule lids were filled with paraffin and a pin was thrust through the paraffin to puncture the apex of the lid. All air was excluded by pressing the lids tightly onto the capsules and the puncture holes were sealed with paraffin. The capsules were placed at $4-6^{\circ} \mathrm{C}$ for 12 hours to permit optimum infiltration without polymerization. The plastic was then placed at room temperature. Polymerization took place from below upward, gel formation occurring at 5-10 hours and early polymerization by $24-36$ hours. Once visible polymerization had occurred in the region occupied by the tissue, the capsule was transferred to an oven at $50-60^{\circ} \mathrm{C}$ where polymerization was completed in 3-5 hours. The gelatin capsule was peeled away and excess plastic removed using an electric rotary saw. The plastic containing the tissue was fastened to a metal slug using epoxy resin. When the resin was hard, the slug was secured in the microtome chuck and sections of 1-3 microns were cut using a rotary microtome and steel knives. Sections were collected in a paper 'boat' and shaken onto a water surface from which they were floated onto methanol-cleaned glass slides.

For embedding biopsy cores in methyl methacrylate, the method of Zambernard et al (1969)을 was modified. A slurry was made by dissolving $25 \mathrm{~g}$ polyethylene glycol distearate, mol wt 1540 (Armak Chemical Division, Philadelphia, Pa) in $150 \mathrm{ml}$ methyl methacrylate monomer (Polysciences, Inc, ?요 Warrington, $\mathrm{Pa}$ ) on a hot plate magnetic mixer at $\overline{5}$ $50-60^{\circ}$ for 10 minutes. Into the solution were mixed $18 \mathrm{ml}$ dibutylphthalate (Polysciences, Inc, Warring- $\delta$ ton, $\mathrm{Pa}$ ) and $2 \mathrm{~g}$ benzoyl peroxide (Eastman Organic $₹$ Chemicals, Rochester, NY). Fifty grams of meth- 음 acrylate polymer VS-100 (Rohm and Haas, Phila- $\rightarrow$ delphia, $\mathrm{Pa}$ ) were then added and dissolved by stirring on a magnetic mixer at room temperature for 4 hours. The slurry could be stored for two weeks in a sealed container in the dark. Before embedding, $N$ tissues were transferred directly from fixative into ${ }_{\omega}^{N}$ $50 \%, 70 \%, 85 \%$, and $95 \%$ ethanol (30 min each) O followed by three changes of one hour in absolute 0 ethanol. Dehydrated tissues were transferred through $\stackrel{\odot}{\Phi}$ two changes of methacrylate monomer, one hour $\stackrel{?}{?}$ each, and placed in a 1:1 mixture of monomer and 7 slurry for 2 hours. The cores were then transferred $\stackrel{P}{\circ}$ to plastic embedding moulds, orientated, covered $\stackrel{\odot}{\stackrel{D}{\circ}}$ with slurry, and placed in a vacuum jar for 2 hours $\mathbb{Q}$ under negative pressure sufficient to cause visible air $\overline{0}$ bubbles to rise slowly. Polymerization was begun 
under long-wave ultraviolet light at room temperature and was complete by 6 hours.

The block face was trimmed to within $2-3 \mathrm{~mm}$ of the tissue using a coping saw, and the block was sectioned with Leitz D-profile steel knives moistened with distilled water. Sections of 2 micron thickness were cut with a Leitz Minot L-1212 rotary microtome and transferred to methanol-cleaned, albuminsubbed glass slides using electron microscopists' forceps. The plastic matrix was softened with a drop of $80 \%$ ethanol and each section was brushed flat with radial strokes of a soft camel hair brush. The slides were placed on a slide-warming stage at $50-60^{\circ} \mathrm{C}$ for at least $\mathbf{4}$ hours before being stained.

Marrow embedded in paraffin exhibited pronounced cell shrinkage and distortion and inadequate definition of primary granules in neutrophils. Embedding in hydroxyethyl methacrylate was a simple procedure, and the histology of marrow so embedded was remarkably good. Because the monomer is soluble in water, residual tissue water did not interfere with infiltration and vigorous dehydration was unnecessary. After fixation with neutral-buffered formalin, glutaraldehyde, or acrolein, cytoplasmic and nuclear shrinkage were negligible. Attempts to apply the technique to larger moulds in order to process whole marrow cores were unsuccessful; the plastic failed to polymerize despite exclusion of air and raised temperature. The technique was therefore applicable only to small fractions of marrow biopsies and the tissue in section was correspondingly small. Because the polymerized plastic was for practical purposes insoluble, the matrix could not be removed from the section. Unfortunately, the plastic stained readily with basic stains, in particular the azures. Differentiation was not effective and the range of staining techniques applicable to such material was limited. Furthermore, polymerization was not dependable; as many as one block in 10 failed to polymerize beyond the phase of gel formation. No explanation for this failure was found. Sections from approximately half of the blocks curled tightly on being cut and could not be flattened for mounting, making serial sectioning impossible. Sections from most blocks were marred by wrinkles in the plastic extending from areas of decalcified bone into the surrounding matrix, frequently obscuring areas of marrow tissue. This distortion was not corrected by altering the hardness of the plastic or the temperature of the block during sectioning, nor did it bear any relation to the degree of decalcification of bony trabeculae as estimated microscopically in stained sections.

Embedding in methyl methacrylate consistently produced blocks of desired hardness. Critical aspects of the procedure were the dehydration phase and the concentration of the constituents of the slurry which determine the hardness of the polymerized plastic. Complete dehydration was essential; residual water prevented infiltration of the block by the monomer and slurry. The final consistency of the polymerized plastic was varied by altering the concentrations of the polyethylene glycol distearate or the moulding powder. Softer blocks were produced by increasing the concentration of polyethylene glycol or moulding powder, whereas harder blocks permitted sectioning of cancellous marrow cores without prior decalcification. Polymerization was found to be most reliable under ultraviolet light at ambient temperature. By this technique $22 \mathrm{~mm}^{3}$ blocks were ready for sectioning 6 hours after initiation of polymerization and exhibited an even consistency throughout and a dependable degree of hardness. The slurry was made up and kept at room temperature in a sealed container in the dark for up to two weeks. Although the mixture became viscous, embedding was successful throughout this period. Cell shrinkage was more pronounced in marrow embedded in methyl than in hydroxyethyl methacrylate. The results, however, represent a striking improvement over paraffin embedding. The matrix was readily removed from sections by xylol or acetone, and the mounted tissue was left free of plastic and ready for siaining.

\section{STAINING}

The following staining methods were evaluated: Wright's stain (Lillie, 1965) with phosphate buffer at pH 4.9, 5.6, and 7·1; Giemsa stain (Lillie, 1965) $1: 10$ and $1: 20$ in phosphate buffer at pH $5 \cdot 6,7 \cdot 1$, and $7 \cdot 4$; azure II-eosine (Block et al, 1953) with and without prior haematoxylin; acid fuchsin $0.1 \%$ in $0.1 \mathrm{~N}$ acetic acid followed by toluidine blue $0.05 \%$ in $0.1 \mathrm{M}$ acetate buffer, $\mathrm{pH} \mathrm{4.0}$; and eosine-y $1.0 \%$ (pH 6) followed by azure II $0.1 \%(\mathrm{pH} 3.5)$ or by toluidine blue $1.0 \%$ in tap water. Stained tissue was differentiated in $95 \%$ acid isopropanol $(1 \%$ glacial acetic acid $\mathrm{v} / \mathrm{v}$ in $95 \%$ isopropyl alcohol), dehydrated in $99 \%$ isopropanol, and cleared through two changes of xylol.

In order to enhance the staining of primary granules in neutrophils, mounted sections were immersed for 5 minutes in sodium hypochlorite, $0.05 \%(w / v)$ in $2 \mathrm{~N} \mathrm{HCl}$, rinsed, and transferred to $0.1 \%$ potassium iodide in $1 \mathrm{~N} \mathrm{HCl}$ until a stable yellow brown colour was developed (approximately 30 seconds) (Ruddell, 1969). The sections were decolourized by immersion in $1 \%$ sodium thiosulphate solution, then washed for 5 minutes in running water, and stained with eosine-y and azure II.

For demonstrating esterase reactivity an incubation solution was made by adding 4 drops of freshly 
diazotized $^{1}$ pararosanaline to $60 \mathrm{ml}$ Michaelis buffer. ${ }^{2}$ The $\mathrm{pH}$ of the solution was adjusted to $6 \cdot 3$ with $0.1 \mathrm{~N} \mathrm{HCl}$. One millilitre naphthyl ASD chloroacetate solution ${ }^{3}$ was added and, after mixing, the incubation solution was filtered. After removal of the plastic, sections were incubated in the filtered solution at $37^{\circ} \mathrm{C}$ for 30 minutes, then rinsed in tap water, and counterstained with toluidine blue $1.0 \%$ or azure II $0.1 \%$ for 15 minutes. The stained tissues were differentiated in $95 \%$ and dehydrated in $99 \%$ isopropanol, cleared in two changes of xylol, and allowed to dry at room temperature. A coverslip was applied over a drop of immersion oil.

Stain evaluation was confined to plastic sections. In hydroxyethyl methacrylate sections stained with Wright's or Giemsa techniques, marrow tissue was inadequately stained and there was heavy blue colouration of the plastic matrix. No improvement was effected by variation of $\mathrm{pH}$, duration of exposure, or stain concentration. More selective staining was achieved with eosine-y and azure II, but background colour complicated evaluation of cytoplasmic characteristics. The best results were obtained with sequential staining by acid fuchsin and toluidine blue. Details of chromatin and nucleoli were clear. The well-defined primary granules in neutrophils were emphasized after exposure to sodium hypochlorite and potassium iodide. Specific granules in eosinophils and mast cells were well stained and granulation in megakaryocyte cytoplasm was well demonstrated. Even in the best sections, however, background staining obscured the cytoplasm of normoblasts and lymphocytes.

Sections of tissue embedded in methyl methacrylate were stained after removal of the plastic. Wright's and Giemsa staining technique produced generalized basophilia, resulting in poor delineation of cytoplasmic characteristics. Differentiation with ethanol provided no improvement, nor did variation in $\mathrm{pH}$ or duration of staining. The best results were obtained with eosine-y and azure II. Initially we used the method described by Block et al (1953), in which the two stains were combined to produce a single staining solution. A fresh solution was required each day, and the precipitation which occurred during mixing made reproducibility uncertain. We therefore stained sequentially, first for 30 minutes with a $1 \%$ solution of eosine-y at pH 6 and then for 15 minutes with a $0.1 \%$ solution of

'Pararosanaline (Sigma Chemical Co, St. Louis, Mo) $40 \mathrm{mg}$ in $1 \mathrm{ml} 2 \mathrm{~N} \mathrm{HCl}$ added to $\mathrm{NaNO}_{2} 40 \mathrm{mg}$ in $1 \mathrm{ml}$ distilled water ${ }^{2}$ Veranol buffer $0.2 \mathrm{M}$ stock diluted $1: 1$ with distilled water and adjusted to $\mathrm{pH} 7 \cdot 0-7 \cdot 2$ with $0 \cdot 1 \mathrm{~N} \mathrm{HCl}$

${ }^{3}$ Naphthyl ASD chloroacetate (Sigma Chemical Co, St. Louis, Mo) $25 \mathrm{~g}$ dissolved in $1.0 \mathrm{ml} \mathrm{N}-\mathrm{N}$ dimethylformamide (J. T. Baker Chem. Co. Phillipsburg, N.J.) azure $\mathrm{II}$ in distilled water (final $\mathrm{pH}$ 3.5-3.7). Origin- 을 ally sections were differentiated in ethanol, which $\overrightarrow{\vec{F}}$ caused excessive fading. Substitution of acid iso- $\stackrel{9}{\rightarrow}$ propanol permitted removal of excess azure without fading of the eosine. Acrolein and glutaraldehyde- $\frac{\bar{\sigma}}{\bar{D}}$ fixed marrow stained in this way displayed clear $\frac{\bar{\sigma}}{\widetilde{D}}$ chromatin patterns, eosinophilic nucleoli, and cyto- $\stackrel{\mathbb{D}}{\square}$ plasmic detail characteristic for each cell line.

Marrow fixed in neutral-buffered formalin for $18 \vec{\circ}$ hours was stained for neutrophil-specific esterase using the ASD chloroacetate substrate (fig 2). This $\vec{\omega}$ procedure produced bright red cytoplasmic granula- $\frac{\Omega}{2}$ tion in neutrophils from the promyelocyte stage to ? completion of maturation.

\section{Discussion}

Marrow aspirates are routinely used for the diagnosis 은 of disorders affecting cellular morphology or distribution. The sample is easily obtained and quickly ready for microscopic evaluation. However, this procedure has several limitations; marrow aspiration $\stackrel{\oplus}{?}$ may fail in myelofibrosis and leukaemia, or may miss $\vec{\theta}$ granulomas, foci of metastatic tumour, lymphoma, के or myeloma. Furthermore, quantitative measurements are unreliable since a proportion of the cells cannot be classified because of damage by smearing, or because of cell loss or sampling error. These factors may all contribute to the reported wide range $\frac{\circ}{\Phi}$ in the neutrophil-erythroid ratio of normal subjects (Williams et al, 1972). Cell destruction does not occur in sections of marrow biopsies, and a definitive diagnosis can be made in cases of lymphoma (Kadin et al, 1971), carcinoma (Grann et al, 1966), or granulomatous disease (Jones et al, 1972) where $\frac{\bar{g}}{8}$ marrow aspirates have failed to demonstrate pathology.

Marrow sections have not been widely used by 8 haematologists because morphological details are $₹$ unfamiliar in cells subjected to fixation, decalcifi- 0 cation, and embedding in paraffin. When tissues are embedded in plastic, however, they exhibit superior histology on light microscopy. Methyl methacrylate has been used successfully for embedding marrow $O$ biopsies (Zambernard et al, 1969; Cathey, 1963; N Burkhardt, 1966). Whereas hydroxyethyl meth- N acrylate offers the advantages of ease of preparation and minimal cell shrinkage, this medium suffers from limitations due to affinity for basic stains and ${ }_{\overparen{D}}$ unreliability of polymerization. Methyl methacrylate $\stackrel{?}{+}$ provides excellent histology, and a wide range of 0 staining methods are applicable (Zambernard et al, $\overrightarrow{\mathrm{O}}$ 1969).

We undertook the present work in order to $\frac{?}{\mathbb{D}}$ compare the merits of hydroxyethyl methacrylate $\frac{\varrho}{\sigma}$ and methyl methacrylate for marrow embedding and 


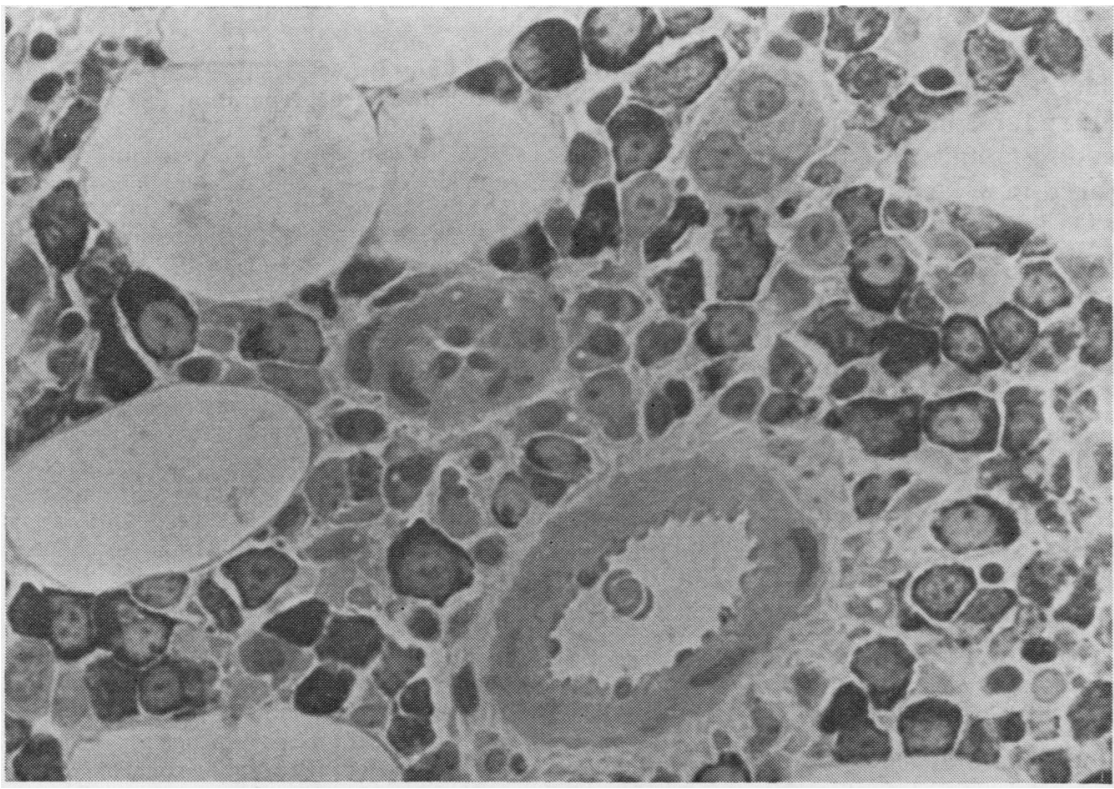

Fig 2 Sectioned human marrow showing esterasepositive cells $(A S D$ ch'oroacetate substrate). The biopsy was fixed in neutral-buffered formalin and embedded in methyl methacrylate. The counterstain is toluidine blue $(\times 400)$.

to develop a method permitting reliable recognition of cells for quantitative purposes (Dancey et al, 1976). An important requirement was that nucleated erythroid cells should be distinguishable from other elements and that neutrophils should be identifiable at all developmental stages.

Acrolein fixation offered optimum cell preservation and staining characteristics. We have found that colour and texture characteristics of cytoplasm, cytoplasmic granules, chromatin, and nucleoli approach those seen in preparations of marrow aspirates, and permit the application of familiar morphological criteria. The cytoplasm of normoblasts was homogeneous and demonstrated a progressive shift from basophilia in early forms to eosinophilia in late forms in parallel with progressive aggregation of chromatin and diminished size. Megakaryocytes displayed cytoplasmic granulation with increasing maturity, plasma cells acquired a characteristic blue cytoplasm frequently with a juxtanuclear clear zone, and mast cells and eosinophils were readily recognizable by their respective large blue and red specific granules. Neutrophil cytoplasm contained mutiple small granules which stained brick red in early promyelocytes and later maturational stages. In the best sections, the cytoplasm of myelocytes, and neutrophils of the postmitotic pool displayed a characteristic faint eosinophilia. Originally Ruddell's (1969) method was used to augment the affinity of anionic groups for basic stains by exposing the sections to sodium hypo- chlorite and potassium iodide. This manoeuvre increased the prominence of primary granules in neutrophils and was particularly useful in glutaraldehyde-fixed marrow. In acrolein-fixed material cytoplasmic granulation was well demonstrated without this step.

In marrow fixed with neutral-buffered formalin, neutrophil-specific esterase activity was demonstrated as a red granular cytoplasmic reaction, permitting rapid evaluation of neutrophil distribution and relative numbers. Mast-cell granules reacted weakly, standing out as large purple inclusions, and occasional reticulum cells contained polychromatophilic reactive material. Nucleoli and chromatin stained blue in sections counterstained with azure II or toluidine blue. Cytoplasm was basophilic in all cell lines.

The following methods are recommended for preparation of marrow sections.

\section{FIXATION}

A Acrolein: $5 \% \mathrm{v} / \mathrm{v}$ in $0.1 \mathrm{~m}$ phosphate buffer, ${ }^{1} \mathrm{pH}$ $\mathbf{7 \cdot 2}$ for 24 hours at room temperature

B Neutral-buffered formalin: $10 \% \mathrm{v} / \mathrm{v}$ formalin in $0 \cdot 1 \mathrm{~m}$ phosphate buffer $\mathrm{pH} 7 \cdot 2$ for 18 hours at room temperature

\section{EMBEDDING}

Following thorough dehydration in ascending con-

${ }^{1}$ Acrolein $1 \mathrm{ml}, 0 \cdot 2 \mathrm{M}$ stock buffer $10 \mathrm{ml}$, distilled water $9 \mathrm{ml}$ 
centrations of ethanol, tissues are transferred from absolute ethanol through two changes of one hour each in methyl methacrylate monomer to a $1: 1$ mixture of monomer and slurry for 2 hours. Tissues are then transferred to embedding moulds, orientated, covered with slurry, and placed in a vacuum jar for 2 hours.

\section{POLYMERIZATION}

Embedded tissues are placed under ultraviolet light at ambient temperature for a minimum of 6 hours.

\section{PROCESSING OF SECTIONS}

The plastic matrix is removed by a 20-minute immersion in acetone and the slides are brought to distilled water through ethanol.

A Sections of acrolein-fixed tissue are transferred after 5 minutes in distilled water to eosine-y $1.0 \%$ for 10 minutes followed by toluidine blue $1.0 \%$, or azure II $0 \cdot 1 \%$ for 15 minutes.

B Sections of neutral-buffered formalin-fixed tissue are placed in the naphthyl ASD chloroacetate incubation solution (see Methods) at $37^{\circ} \mathrm{C}$ for 30 minutes, rinsed in tap water, and counterstained with toluidine blue $1.0 \%$ or azure II $0.1 \%$ for 15 minutes.

This work was supported by research grants HL06242 and HL-11775 and training grant AM-05130 from the National Institutes of Health. Fellowship stipend support was provided by the Medical Research Council of Canada (Dr Dancey) and by the Swiss National Foundation (Dr Deubelbeiss). A portion of this work was conducted through the Clinical Research Center's facility of the University of Washington with the support of grants FR-37 and FR-133 from the National Institutes of Health.

\section{References}

Block, M., Smaller, V., and Brown, J. (1953). An adaptation of the Maximow technique for preparation of sections of hematopoietic tissues. J. Lab. clin. Med., 42, 145-151.

Burkhardt, R. (1966). Präparative Voraussetzungen zur klinischen Histologie des menschlichen Knochenmarks. Blut, 13, 337-357.

Cathey, W. J. (1963). A plastic embedding medium for thin sectioning in light microscopy. Stain Technol., 38, 213-216.

Dancey, J. T., Deubelbeiss, K. A., Harker, L. A., and Finch, C. A. (1976). Neutrophil kinetics in man. J. clin. Invest. (In press).

Ellis, L. D., Jensen, W. N., and Westerman, M. P. (1964). Needle biopsy of bone and marrow: an experience with 1,445 biopsies. Arch. intern. Med., 114, 213-221.

Grann, V., Pool, J. L., and Mayer, K. (1966). Comparative study of bone marrow aspiration and biopsy in patients with neoplastic disease. Cancer (Philad.), 19, 1898-1900.

Jamshidi, K. and Swaim, W. R. (1971). Bone marrow biopsy with unaltered architecture: a new biopsy device. J. Lab. clin. Med., 77, 335-342.

Jones, S. E., Rosenberg, S. A., and Kaplan, H. S. (1972). Non-Hodgkin's lymphomas. I. Bone marrow involvement. Cancer (Philad.), 29, 954-960.

Kadin, M. E., Glatstein, E., and Dorfman, R. F. (1971). Clinicopathologic studies of 117 untreated patients subjected to laparotomy for the staging of Hodgkin's Disease. Cancer (Philad.), 27, 1277-1294.

Lillie, R. D. (1965). Histopathologic Technic and Practical Histochemistry, 3rd edition, chapter 32. McGraw-Hill, New York.

Mori, M., Ito, M., and Fukui, S. (1965). Decalcification for histochemical demonstration of hydrolytic and oxidative enzymes. Histochemie, 5, 185-195.

Ruddell, C. L. (1967). Embedding media for 1-2 micron sectioning. II. Hydroxyethyl methacrylate combined with 2-butoxyethanol. Stain Technol., 42, 253-255.

Ruddell, C. L. (1969). The demonstration of anions generated by the action of sodium hypochlorite $(\mathrm{NaOCl})$ on tissue sections, including observations on the unmasking of carbonyl groups. Histochemie, 19, 319-339.

Williams, W. J., Butler, R., Erslev, A. J., and Rundles, R. W. (1972). Hematology, p. 26. McGraw-Hill, New York.

Zambernard, J., Block, M., Vatter, A., and Trenner, L. (1969). An adaptation of methacrylate embedding for routine histopathologic use. Blood, 33, 444-451. 